\title{
A representação da Educação Física na 18ª temporada da telenovela Malhação
}

CDD. 20.ed. 796.017

796.05

http://dx.doi.org/10.1590/1807-55092015000100095

\author{
Cássia Marques CÂNDIDO* \\ Monique Ribeiro de ASSIS ${ }^{* *}$ \\ Nilda Teves FERREIRA* \\ Lúcia Aparecida Martins Campos COELHO** \\ *Departamento de \\ Educação Física, Uni- \\ versidade Gama Filho. \\ **Instituto de Educação \\ Física e Desportos, \\ Universidade do Esta- \\ do do Rio de Janeiro.
}

\section{Resumo}

Esta pesquisa foca a imagem profissional da Educação Física considerando a notoriedade que a mesma adquiriu na televisão ao longo dos últimos anos. 0 objetivo é explicitar alguns dos sentidos relacionados à abordagem da Educação Física escolar presentes na $18^{a}$ temporada de Malhação, telenovela exibida pela Rede Globo. 0 método utilizado para nortear a investigação sobre o processo de produção de sentidos é a Análise do Discurso. Acerca dos resultados, evidenciamos que as situações de aula foram construídas com base em modalidades esportivas diferenciadas para meninos e meninas, privilegiando a técnica de execução dos gestos. Também foi marcante a dificuldade apresentada pelo professor ao lidar com questões que extrapolavam esta dimensão técnica. A abordagem midiática do profissional idoso no espaço escolar se configurou como novidade, porém, não permaneceu na temporada seguinte.

Palavras-ChaVe: Televisão; Imagem profissional; Professor idoso; Técnica; Competição.

\section{Introdução}

O interesse pelo fenômeno midiático relacionado à Educação Física surgiu a partir do entendimento que a televisão é de acordo com Bourdieu ${ }^{1}$ um poderoso instrumento de manutenção da ordem simbólica; tendo, por isso, a capacidade de influenciar a formação de opiniâo dos telespectadores. Especificamente sobre a cultura corporal de movimento, BETTI ${ }^{2}$ explica que a mídia tem papel de destaque na construção de sentidos, por isso, é preciso que os profissionais se posicionem criticamente diante dos produtos midiáticos.

Nesta perspectiva, objetivamos explicitar alguns dos sentidos relativos à Educação Física escolar presentes na $18^{a}$ temporada de Malhação, telenovela exibida pela Rede Globo de Televisão. A relevância da pesquisa está, sobretudo, na constatação de que a Educação Física ocupa cada vez mais espaço na mídia, constituindose ainda um recorte pouco explorado no que confere à abordagem da imagem profissional. Pires et al. ${ }^{3}$ atestam que, de fato, há escassez de estudos dedicados à compreensão de questôes deste gênero.

$\mathrm{Nas}$ telenovelas exibidas pela emissora em questão, geralmente os profissionais de Educação Física exibem corpos jovens e atléticos, tendo na maioria das vezes, as suas imagens associadas à conquista $\mathrm{e}$ sedução. Um destes exemplos ocorreu na novela "Pé na Jaca" exibida no ano de 2007, onde Lance, personagem interpretado pelo ator Marcos Pasquim, tentava seduzir as alunas da academia. Atuando como professor de Educação Física sem possuir formação acadêmica, o personagem causou grande descontentamento por parte de diversos profissionais da área, que recorreram ao Conselho Federal de Educação Física, conseguindo que o personagem fosse removido da funçáo conforme explica CONFEF ${ }^{4}$.

Em Malhação, telenovela produzida para o público jovem, a abordagem da Educação Física também é frequente, ocorrendo de modo bastante semelhante aos exemplos mencionados. Entretanto, na $18^{\text {a }}$ temporada do programa, identificamos uma ocorrência bem diferente das demais. Trata-se da exibição do personagem Agenor, interpretado pelo ator Valter Breda, que representou um profissional de Educação Física idoso trabalhando no espaço escolar. Além da idade, aspectos referentes ao seu 
comportamento, espaço de trabalho e metodologia utilizada em aula também nos despertaram atenção. Assim, optamos pela análise deste caso, não por julgá-lo mais representativo que os demais, e sim pelo que apresentou de novo ao contexto da Educação Física abordada nas telenovelas.

\section{Breve contextualização de Malhação até a estreia de Agenor}

Segundo o Projeto Memória da Rede Globo 5 a telenovela Malhação é exibida pela Rede Globo desde o ano de 1995, sendo produzida para o público jovem. Dentre as propostas do programa está a abordagem de temáticas ligadas à realidade da juventude na interação com a família e com a sociedade. A trama envolve assuntos sobre relacionamentos amorosos, aborto, AIDS, virgindade, entre outros. A exibição do programa ocorre de segunda a sexta-feira, preenchendo o horário entre a sessão da tarde e a novela das seis.

Ainda na perspectiva do Projeto Memória da Rede Globo 5 é possível constatar que até o ano de 2013 o programa conta com um total de 21 temporadas que se transformaram múltiplas vezes. Durante esse período o professor de Educação Física foi representado por vários personagens. Dentre os exemplos apresentados, mencionamos: a) Paula Prata representada pela atriz Silvia Pfeifer, que apesar de ser formada em Educaçáo Física atuava somente na administração da própria academia de ginástica; b) Dado representado pelo ator Cláudio Heinrich; c) Rodrigo representado por Nicolas Trevijano. Além destes, constatamos exemplos mais recentes que são:
Agenor, foco desta análise; e Marcela, personagem interpretada por Danielle Winits.

O Projeto Memória da Rede Globo ${ }^{5}$ demonstra que no período da estreia, o cenário da telenovela era uma academia de ginástica localizada no bairro Barra da Tijuca, na cidade do Rio de Janeiro. Embora com modificaçóes, esse ambiente permaneceu no programa durante as três primeiras temporadas até o ano de 1997. Em 1998 o ambiente deixou de ser academia, variando entre espaços como praia, bar, entre outros. Em 1999, já na sexta temporada, passa a fazer parte do cenário o colégio Múltipla Escolha.

Segundo TVG ${ }^{6}$ esse cenário permanece no ar até o ano de 2009, quando termina a temporada do programa. Então, entra em cena o Colégio Primeira Opção, também destinado a estudantes de classe média, se mantendo como cenário principal durante duas temporadas até o ano de 2011. É neste período que Agenor passa a fazer parte da trama, especificamente no capítulo exibido no dia 23 de dezembro de 2010 , já na $18^{a}$ temporada do programa.

A contextualização do personagem ocorre num período em que o programa abordava a problemática enfrentada pelos idosos na sociedade. Além de professor de Educação Física aposentado, Agenor era avô de duas personagens, ilustrando expressivamente essa temática através das dificuldades que encontrava no cotidiano familiar e também no mercado de trabalho. Possuindo quase 70 anos de idade (informação verbal) ${ }^{a}$, o personagem apresentou-se fisicamente ativo, conseguindo retornar ao mercado de trabalho sendo contratado para atuar no ambiente escolar.

\section{Método}

Esta pesquisa é de natureza qualitativa, sendo norteada pelo referencial teórico da Análise do Discurso (AD) segundo a perspectiva de ORLANDI ${ }^{7-10}$. ORLANDI ${ }^{9}$ aponta algumas especificidades sobre o discurso midiático e afirma que, diferente do que ocorre no discurso interpessoal, a materialidade da memória produtora de texto da mídia é metálica, caracterizada pela informatização dos arquivos, fazendo com que o saber discursivo seja muitas vezes reduzido "[...] a um pacote de informaçóes, ideologicamente equivalentes [...]" (p.16). Neste contexto, a autora afirma que o espaço de interpretaçáo é regido pela opinião dos telespectadores.

Assim, analisamos o processo de produção dos sentidos, considerando que o enredo de Malhação é produzido para um espectador imaginário, equivalente ao leitor virtual proposto por ORLANDI ${ }^{7}$, ou seja, "[...] aquele que o autor imagina (destina) para o seu texto e para quem ele se dirige" (p.9). Trata-se do mecanismo da antecipação no qual a autora afirma que "o sujeitoautor projeta-se imaginariamente no lugar em que o outro o espera com sua escuta e, assim, "guiado" por esse imaginário, constitui, na textualidade, um leitor virtual que lhe corresponde, como seu duplo (p.61)".

Também é importante mencionar que a $\mathrm{AD}$ possibilita segundo ORLANDI ${ }^{10}$ reflexóes que extrapolam as formas materiais da linguagem. Por isso, apresentamos algumas imagens retiradas das cenas no intuito de favorecer a compreensão das discussões. 
Sobre o processo de seleção dos dados, inicialmente realizamos um reconhecimento dos mesmos assistindo a todos os capítulos da $18^{\mathrm{a}}$ temporada de Malhação. As atenções foram direcionadas às cenas em que o contexto da Educação Física se fizeram presentes. A coleta dos materiais ocorreu através do acesso a "homepage" da telenovela ${ }^{11}$, que disponibiliza por determinado tempo os capítulos da mesma, bem como informaçốes sobre os personagens.

A partir de então selecionamos cenas para análise, considerando aquelas que melhor evidenciavam as questôes abordadas pelo estudo, conscientes de acordo com Rose ${ }^{12}$ que:

Todo passo, no processo de análise de materiais audiovisuais, envolve transladar. E cada translado implica em decisões e escolhas. Existirão sempre alternativas viáveis às escolhas concretas feitas, e o que é deixado fora é tão importante quanto o que está presente (p.343).

Acerca da apresentação das discussōes e resultados, dividimos em etapas complementares. Primeiro evidenciamos a produção de sentidos relativos à idade do professor, por considerar que o contexto que envolve este assunto fornece pistas sobre os significados ligados à Educação Física abordada. Em seguida, clarificamos alguns sentidos sobre a atuação profissional a partir dos seguintes elementos: informaçóes presentes na entrevista que resultou na contratação de Agenor, conteúdo trabalhado em aula; didática utilizada e estratégias requisitadas para resolver conflitos. Em ambas as etapas, apresentamos cenas e transcrevemos diálogos.

$\mathrm{Na}$ abordagem das imagens estivemos atentos ao processo de ediçáo, que segundo Hernandes ${ }^{13}$

\section{Resultados e discussão}

\section{Exposição das cenas e diálogos}

As cenas requisitadas abaixo possibilitam a discussão de, pelo menos, dois eixos relativos à educação física representada. Trata-se de questóes que aparecem de modo imbricado, relacionando-se à geração, em termos etários, e à imagem profissional, onde são explicitados indícios sobre significados relativos ao ensino da educação física abordada na produção do enredo. De acordo com Orlandi ${ }^{10}$ os sentidos permeiam o discurso se constituindo de modo irregular, ou seja, não se apresentam linearmente. Por isso, a fim de facilitar a compreensão, expomos consiste "[...] na seleção, organização e montagem de todos os elementos que devem formar um programa [...]” (p.84). Neste sistema, a utilizaçáo dos planos de câmera tem grande importância, pois, na visão do autor trata-se de um recurso que possibilita a captação e manipulação da atenção do telespectador, de modo a influenciar o processo de construção dos sentidos. Assim, o conhecimento destes efeitos favorece a interpretaçáo das cenas e o entendimento das ideias e intençóes do diretor.

Os planos de câmera diferem entre si pela distância da câmera até o objeto ou personagem que está sendo filmado. Quanto à nomenclatura, não há padronização, então, utilizamos os termos apresentados por HERNANDEs ${ }^{13}$ como veremos a seguir:

a) Plano geral: utilizado no início de uma sequência para passar uma referência mais específica do local onde ocorre a açáo. No plano geral o espaço é ressaltado, enquanto a imagem do personagem é dissolvida. Trata-se de uma dimensão mais inteligível na qual o telespectador é solicitado a fazer relaçóes entre objetos, pessoas e o espaço;

b) Plano de conjunto: utilizado para diminuir um pouco o foco no ambiente, concentrando-se um pouco mais nos personagens. É passada uma noção de conjunto, apresenta-se um grupo de pessoas no cenário. É um plano que permite reconhecer os atores e a movimentação de cena e não deve ser pensado em nível de enquadramento corporal;

c) Plano próximo: utilizado para enquadrar o personagem do tórax até a cabeça. Há maior valorização do personagem e menor valorizaçáo do ambiente. As relaçóes se estreitam ainda mais, possibilitando a percepção da emoçáo do personagem.

todo o contexto para em seguida discuti-lo em dois tópicos distintos.

Como ponto de partida trazemos a tona os acontecimentos que marcaram o dia em que Agenor foi ao Colégio Primeira Opção ser entrevistado. A cena ilustrada na FIGURA 1 inicia com a utilização do plano geral de câmera, sendo possível observar a chegada de Agenor à escola. Sua intençáo era conquistar a vaga de professor de educação física para atuar no ensino médio. Ao adentrar no ambiente ele se encontra por acaso com o aluno Marcos, o qual conhecia e náo gostava devido a atitudes que perpassavam discriminação pelo idoso. 


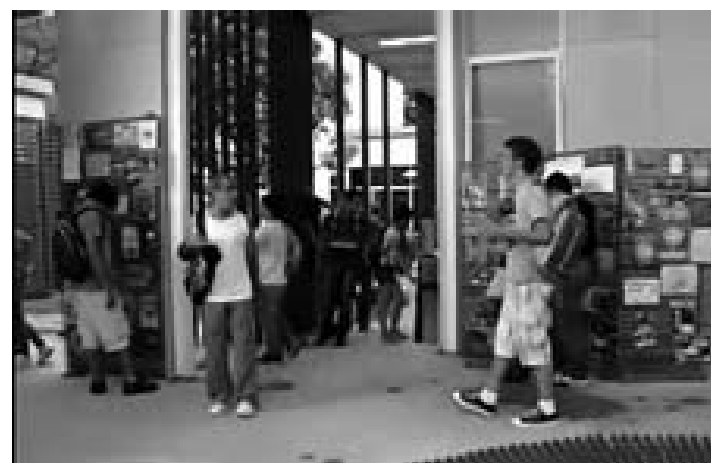

FIGURA 1 - Cena extraída do capítulo exibido no dia 29/12/ 2010.

Após a aproximação transcorrem os seguintes dizeres:

Marcos: - Oh! Eu posso saber o que o velhote tá fazendo aqui?

Agenor: - Eu posso ser o seu novo professor de educação física. Já pensou que delícia? Íamos nos ver toda semana!

Marcos: - E eu posso saber que modalidades o vovô vai ensinar? Não, peraí; deixa eu imaginar. Dominó com barreira, biribim ornamental ou corridinha de bengala?

Agenor: - Fique sabendo que entre outras coisas, eu vou dar noçóes de defesa pessoal para que os meus alunos possam se defender dos maus elementos.

Marcos: - Isso, você acabou de encontrar um mau elemento. E agora? Vamos ver se o senhor sabe se defender?

A FIGURA 2 exibe Agenor imobilizando Marcos como resposta às provocaçóes ocorridas. Através do plano conjunto de câmera observamos que o fato é presenciado por outros alunos que reagem com risos e surpresa.

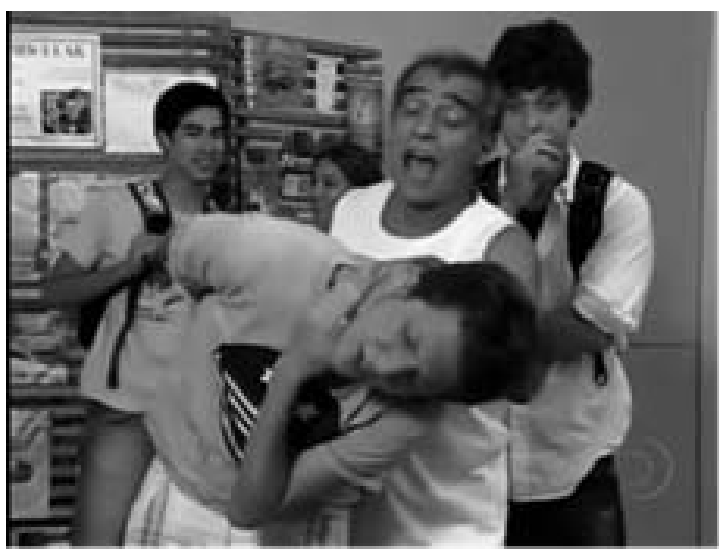

FIGURA 2 - Cena extraída do capítulo exibido no dia 29/12/ 2010
A cena subsequente demonstra a trajetória de Agenor momentos depois do acontecimento. Ilustrada na FIGURA 3, e produzida com a utilizaçáo do plano conjunto de câmera, observamos o momento em que Agenor é entrevistado. Ele se encontra na sala da diretora Tereza, sentado diante dela e ao lado da coordenadora Vera interpretada pela atriz Cristina Nicolotti.

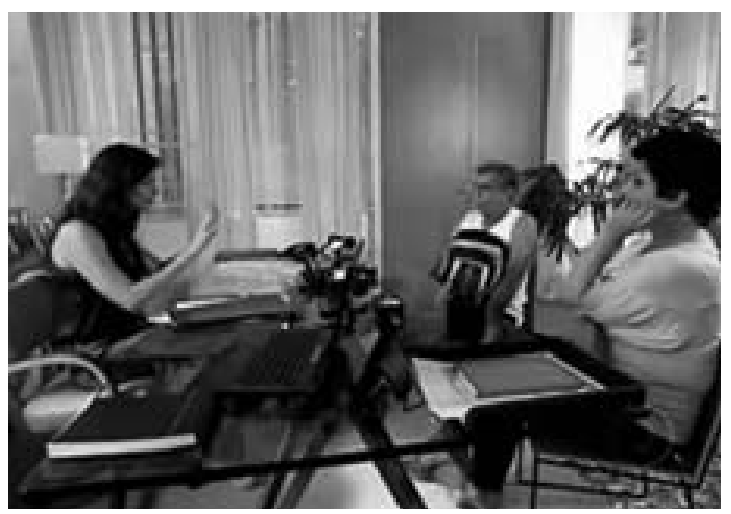

FIGURA 3 - Cena extraída do capítulo exibido no dia 29/12/ 2010.

Na FIGURA 4 o plano próximo nos permite perceber o estado emocional de Agenor. A expressão facial e os ombros encolhidos demonstram tensão.

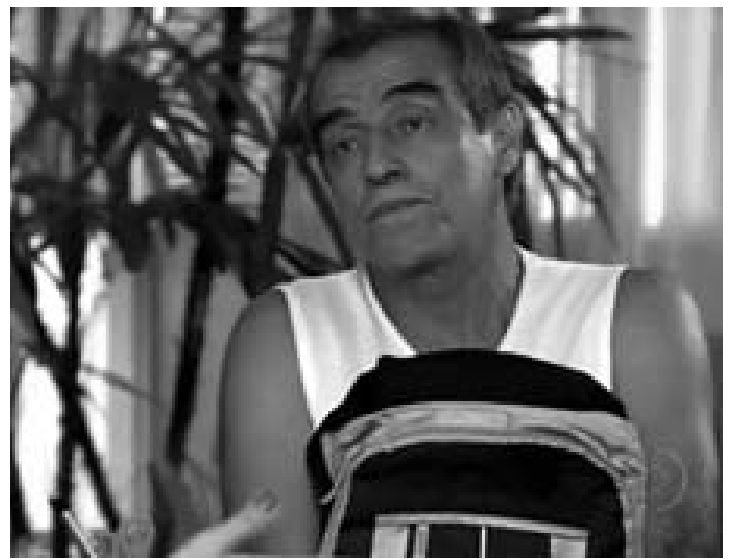

FIGURA 4 - Cena extraída do capítulo exibido no dia 29/12/2010.

A mochila posicionada na frente do corpo denota uma atitude defensiva, que se mantém durante o diálogo, do qual destacamos alguns trechos:

Tereza: - Como é que o senhor se definiria, assim, pessoalmente?

Agenor: - Eu sou honesto, trabalhador, obstinado. Entendo muito do que faço. Tenho didática, mas, sou velho; e às vezes sou chato.

[...] 
Tereza: Muito bom o seu currículo. Eu só não estou reconhecendo esta faculdade que o senhor se formou.

Agenor: É a UEG era a Universidade da Guanabara, mudou de nome em 1975 depois da fusão com o Estado do Rio de Janeiro. E como vocês podem ver eu sou um camarada meio antigo.

[...]

Tereza: - Pra essa função de professor de educação física o condicionamento físico é muito importante, porque a gente promove olimpíadas escolares, treinamentos de times. Enfim, o senhor acha que pode assumir essas responsabilidades?

Agenor: - Isso não vai ser problema. Mas eu vou entender se vocês preferirem contratar uma pessoa mais jovem; porque é isso que vocês querem, não é? Um professor jovem. Podem falar a verdade, vocês não tem interesse em contratar um idoso como professor.

Tereza: - Ei, ei, por que o senhor parte do princípio que experiência de vida é desvantagem?

Agenor: - Eu já tentei outras vezes arrumar emprego e estou cansado de ouvir que eu estou em idade avançada.

Tereza: - Bom, eu vou mentir pro senhor se disser que não vou levar em consideração a sua idade, é claro que eu vou. Agora, eu te garanto que isso não vai ser definitivo; nem por bem, nem por mal.

Agenor: - Então, nada me resta a não ser esperar. Mas de qualquer forma eu agradeço muito a atenção das senhoras.

Vera: - Não, aonde você vai Agenor?

Agenor: - A diretora mesmo acabou de dizer que vai levar em consideração a minha idade e então...

Tereza: - E então o senhor está contratado por um período de experiência e, se tudo der certo, será contratado definitivamente.

\section{A idade como um "carrasco" na vida de Agenor}

Seguindo a ordem de ocorrência, iniciamos a análise pelos dizeres do aluno Marcos e verificamos que ele repudia a possibilidade de ter um professor de educação física idoso. Sua fala advém de um imaginário que limita a prática de ensino do professor de educação física a demonstrações que dependem essencialmente de aptidão física. $\mathrm{O}$ jovem demonstra acreditar que devido à idade, Agenor só é capaz de ensinar conteúdos que exigem pouca mobilidade. Trata-se de uma visão que considera o envelhecimento sob um ponto de vista generalista.

Por outro lado, sob a ótica da diretora a imagem é outra, pois, mesmo havendo preocupação com a aptidáo física, somente a idade não representa empecilho para a contratação. No entanto, fica evidente que Agenor teme não conseguir a vaga em função da idade que possui. Ele antecipa conclusóes demonstrando-se refém de experiências anteriores nas quais era discriminado. LUdORF e ORTEGA ${ }^{14}$ discutem a origem do sentimento que aflige professores de educação física em idade avançada, e afirmam que tensões semelhantes as que observamos no comportamento de Agenor são comuns, inclusive costumam transparecer de modo contraditório em relação à segurança que poderiam expressar em função da experiência adquirida.

Silva e Ludorf ${ }^{15}$ explicam que existem particularidades no modo como o professor de educação física lida com o próprio envelhecimento. Os autores oferecem interpretaçóes subsidiadas em aspectos culturais tipicamente contemporâneos, e apontam especificidades ligadas ao significado que o corpo adquire no contexto da profissão que o tem como referencial. Dentre os aspectos discutidos, destacam-se as preocupaçóes com a deterioração da capacidade funcional do corpo, bem como, com as tensóes ligadas ao risco de adoecer, perder a lucidez e a capacidade de inovar.

Referindo-se ao contexto que envolve a totalidade das pessoas, Courtine ${ }^{16}$ explica que a partir de 1980 surge nos Estados Unidos da América uma intensa busca pelo corpo magro e musculoso. $\mathrm{O}$ autor afirma que esse acontecimento ocasionou grande crescimento no consumo de produtos e serviços como, por exemplo, aparelhos de ginástica e suplementos alimentares desenvolvidos com a finalidade de propiciar o corpo desejado. Essa transformação, chamada de gerenciamento do corpo, refletiu em todo o Ocidente se pautando na:

[...] obsessão dos invólucros corporais: o desejo de obter a tensão máxima da pele; o amor pelo liso, pelo polido, pelo fresco, pelo esbelto, pelo jovem; ansiedade frente a tudo que na aparência pareça relaxado, franzino, amarrotado, enrugado, pesado, amolecido ou distendido; uma contestação ativa das marcas do envelhecimento no organismo. Uma negação laboriosa de sua morte próxima ${ }^{17}$ (p.86).

A fim de ampliarmos a reflexão sobre o envelhecimento recorremos ao imaginário mítico ligado à Cronos. Chevalier e Geerbrant ${ }^{17}$ explicam que na mitologia grega Cronos decepa os testículos do pai, destronando-o. Então na tentativa de evitar que ocorresse o mesmo devido à progenitude, Cronos passa a devorar os próprios filhos, exceto Zeus, o qual a mãe (Reia) ajuda fugir em segredo. Quando adulto Zeus faz com que Cronos vomite de modo a devolver todos os filhos, depois o mutila abrindo a segunda geração dos deuses. Este enredo gera “[...] 
o sentimento de uma duraçáo que se esgota [...]. Simboliza também o medo de um herdeiro, de um sucessor, de um substituto" (p.307).

Esta interpretação pode se relacionar à noção de tempo cronológico. Assim, em se tratando de idade, o tempo representa imposição de limites tornandose castrador, fazendo com que o envelhecimento seja percebido de forma negativa, causando, entre outros sentimentos, a rejeição. Transportando tal raciocínio para o contexto da educação física e considerando características específicas da cultura Ocidental, torna-se compreensível que o avanço da idade traga preocupação para o profissional, e possível preconceito por parte de alguns alunos.

Acerca do âmbito midiático, Dela-Silva ${ }^{18}$ afirma que é comum as telenovelas contextualizarem acontecimentos que poderiam de fato ocorrer na vida dos telespectadores. De acordo com Lopes ${ }^{15}$ temas ligados ao preconceito, por exemplo, são colocados em pauta na telenovela como "social real" (p.368), ou seja, aborda assuntos relativos a problemáticas sociais, possibilitando que sejam pensados e discutidos no interior de diferentes grupos. $\mathrm{Na}$ visão do autor esta dinâmica "opera como fator de redução da distancia entre geraçóes, alivia diferenças e facilita o entendimento entre os envolvidos, desde que estejam abertos para a comunicação" (p.372).

Além disso, de acordo com Coutinho e QuarTIEIRO $^{19}$ o mesmo programa pode ser endereçado a diferentes públicos, e no caso específico de Malhaçâo, além dos jovens, outras faixas etárias assistem ao programa. Através de dados disponibilizados pelas Notícias da TV brasileira ${ }^{20}$ que divulgam informaçóes sobre as programações televisivas nacionais, constatamos que considerável percentual dos espectadores de Malhação é adulto, inclusive possui idade superior a 50 anos.

Assim, considerando o leitor virtual apontado por ORLANDI $^{7}$, compreendemos que a abordagem da temática relacionada ao idoso, e por consequência a idealização do contexto representado por Agenor, pode significar uma tentativa de aproximação com este público. Ao resgatar a dimensão vivida na educação física, a telenovela possibilita ao telespectador o estabelecimento de uma rede de memórias e identificações que não se esgotam nas práticas corporais, podendo evocar momentos da história de vida dos telespectadores em questão.

E por fim, ao refletirmos sobre o perfil etário dos professores de educação física apresentados no início deste estudo, verificamos que Agenor é o único personagem que representa um idoso exercendo a profissão.
Dentre os exemplos mencionados somente ele e Paula Prata não são jovens como os demais personagens abordados. No entanto, em se tratando de Paula Prata, apesar de ficar declarado que ela é profissional formada em Educação Física, seu trabalho se limita ao setor administrativo da própria academia, enquanto o trabalho específico é exercido por professores jovens.

Provavelmente a atuaçáo de Agenor no ambiente escolar se justifica com base na representação do compromisso que esta instituiçáo assume diante das questōes humanas e sociais. Tal finalidade supera a perspectiva meramente biológica, muitas vezes valorizada em espaços como academias de ginástica, onde a prática profissional é permeada essencialmente pelo consumo.

\section{Características das aulas}

Ao direcionarmos as atençóes para a reação de Agenor, na primeira cena descrita, constatamos que quando ele tenta descontruir o imaginário generalista de Marcos, ele lança mão de conhecimentos que requerem habilidades específicas, demonstrando possuir além de coragem e força física, domínio das técnicas de defesa pessoal. Além de indicar que Agenor é fisicamente ativo, o contexto permite observar $o$ argumento que justifica o ensino de tal conteúdo. Abordando técnicas de lutas para os alunos se defenderem dos maus elementos, verificamos que o professor privilegia a técnica, se distanciando das propostas recentes sobre o ensino de lutas na escola.

Embora este estudo não tenha o objetivo de enquadrar os significados que permeiam o produto midiático em pauta no campo teórico atual, estabelecendo comparaçōes; esta estratégia é requisitada em algumas situações por permitir que haja melhor identificação dos significados que emergem da representação.

Sendo assim, NAscimento e Almeida ${ }^{21}$ afirmam que a inclusão do ensino de lutas na escola se deve a mudança paradigmática que incluiu o conceito de cultura no âmbito da educação física. $\mathrm{Na}$ visão dos autores, para que ocorra efetivaçâo deste item no currículo e principalmente no cotidiano das aulas é preciso superar percalços que restringem sua abordagem por parte dos profissionais. Neste contexto uma das dificuldades identificadas é a crença de que a violência está imbricada na luta, ou mesmo que é necessário dominar tecnicamente o conteúdo para entáo requisitá-lo. $\mathrm{Na}$ ótica dos autores estas restriçôes podem ser relativizadas ficando na dependência de metodologias adequadas. Além disso, So e BETTI ${ }^{22}$ indicam que a perspectiva técnica não é a que deve ter mais ênfase na escola. 
E ainda, segundo os Parâmetros Curriculares Nacionais (PCNs) ${ }^{23}$ o planejamento do ensino de lutas no ambiente escolar deve ser cauteloso, englobando reflexóes que considerem aspectos relativos à sua filosofia. Nesta perspectiva, trata-se de um conteúdo que deve ser oportunizado a totalidade dos alunos, sendo de grande relevância para abordar discussóes sobre a violência nas cidades, perpassando temas como brigas, confrontos entre torcidas organizadas, entre outros. Além disso, as aulas devem ser elaboradas considerando as dimensões conceituais, procedimentais e atitudinais dos conteúdos, que respectivamente diz respeito ao saber, saber fazer e saber ser.

Desta maneira, retomando a dinâmica da cena e partindo de breve compreensão sobre a inserção das lutas no currículo da educação física, se torna visível que as expectativas técnicas expressas pertencem a um ideário que não atinge a plenitude pedagógica do conteúdo. Entretanto, o imaginário presente na produçáo do enredo pode ser constatado também na prática profissional, bem como apontou NASCIMENTo e Almeida ${ }^{21}$.

Migrando para outro aspecto que nos chamou atenção, analisamos os dizeres da diretora durante a entrevista. Trata-se da preocupação com o condicionamento físico do professor de educação física, por causa da promoção de treinamentos e competiçóes que deveriam acontecer caso Agenor assumisse a vaga. $\mathrm{Na}$ ocasiáo transparece a expectativa de que as aulas aconteçam potencializando a técnica e a competição. GHIRALdelli JúNIOR ${ }^{24}$ ao discutir a perspectiva competitiva das aulas de educação física, aponta que neste contexto são valorizados os treinamentos voltados para o aprimoramento desportivo.

Inclusive, mesmo não sendo o único autor a tratar do assunto, a forma linear de descrever o modelo competitivo utilizada por GHIRALDELLI JúNIOR ${ }^{24}$ expressa com grande clareza os significados que emergem da fala diretora. Segundo o autor, o modelo competitivo foi difundido no período compreendido principalmente entre os anos 1960 e 1970, época em que os esportes passaram a fazer parte da formação do profissional de educação física. Então, considerando o período de formação, a faculdade (atual UERJ) e a resolução no 425/74 ${ }^{25}$ que regeu o curso de educação física da universidade mencionada, observamos não se tratar de coincidência a naturalidade expressada por Agenor ao tomar conhecimento das expectativas $\mathrm{da}$ diretora. Inclusive ele se mostra disposto a executar o projeto com dedicação.

Todavia, vale clarificar que a lógica esportiva pautada na competição ainda é comum nas aulas de educação física escolar brasileira. Partindo de um recorte que apresenta este fundamento, Frizzo ${ }^{26}$ evidencia fatos políticos que contextualizam a criação das olímpiadas escolares, apontando tradição relacionada a esta prática ainda na atualidade. $\mathrm{O}$ caráter excludente e utilitarista que a educação física adquire quando lança mão exclusivamente desta dinâmica de trabalho é causador de grande insatisfação, o que faz com que muitos profissionais se dediquem à procura de alternativas para superar a questão.

Hildebrandt-Stramann ${ }^{27}, \mathrm{Kunz}^{28}, \mathrm{BraCHT}^{29}$ representam alguns dos exemplos que investem na modificação do gênero meramente técnico e competitivo das aulas. Embora defendam pontos de vista diferentes, estes autores trouxeram considerável avanço ao campo de conhecimento da educação física escolar. Todavia, conforme afirma FrIzzo ${ }^{26}$, no cotidiano escolar atual também é possível verificar aulas essencialmente tradicionais. Na perspectiva do autor, o conhecimento e a reflexáo sobre projetos inovadores relativos à metodologia de ensino ficam, muitas vezes, restritos ao período de formação profissional.

$\mathrm{Na}$ esfera midiática Lopes ${ }^{30}$ explica que a telenovela representa o cotidiano de forma que "o enredo e a trama que envolvem os personagens representam a vida diária em determinado local e tempo" (p.363). Segundo o autor esta forma de contextualizar representaçóes costuma gerar insatisfação e conflitos. No entanto, não poderíamos expressar indignação apenas pela representação utilizada na descriçáo do recorte, pois, embora as características explícitas sejam retiradas de um período específico da história, sendo desconsideradas as transformaçóes ocorridas em períodos subsequentes, constatamos que no cotidiano escolar práticas caracteristicamente tradicionais ainda são efetivadas.

\section{As aulas de Educação Física em Malhação}

Nesta etapa do estudo é possível explicitar que a perspectiva competitivista da Educação Física, sugerida na entrevista inicial do professor Agenor, predominou ao longo do enredo ligado às situaçóes de aula. Então, no que se refere a estes momentos, destacamos alguns dos aspectos que nos chamaram atenção. O primeiro deles é a separação de meninas e meninos por turma. Outro fator se refere aos conteúdos e metodologia utilizados, pois, identificamos a prática exclusiva de duas modalidades esportivas na perspectiva técnica. Além disso, o professor demonstrou despreparo ao lidar com problemáticas sociais típicas da atualidade. 
Sobre a separação dos alunos em função do sexo, o plano geral de câmera utilizado para produzir a cena ilustrada na FIGURA 5, nos permite constatar a prática do voleibol. Trata-se do único momento em que uma situação de aula das meninas apareceu. No enredo, Agenor acompanha o jogo fazendo a arbitragem. Após curta sequência de jogadas, caracterizada por erros sucessivos, uma das alunas sente-se mal, pedindo para se retirar. Uma colega pede autorização para acompanhá-la, e logo o jogo prossegue ocorrendo rapidamente o desfecho da cena.

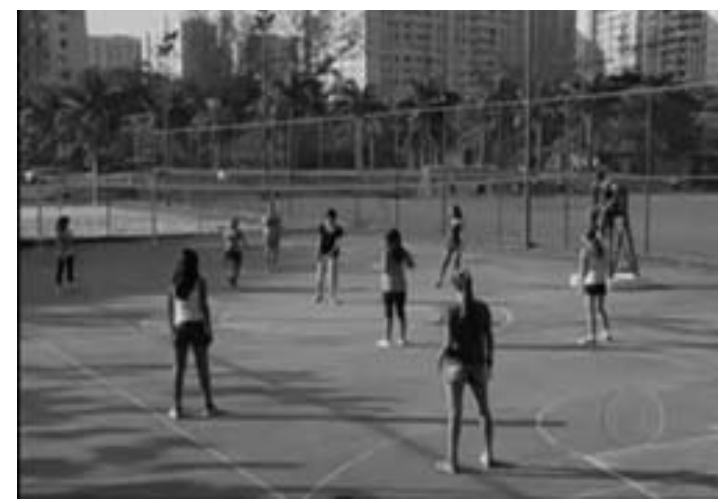

FIGURA 5 - Cena extraída do capítulo exibido no dia 21/04/2011.

Já sobre as aulas destinadas aos meninos, constatamos que foram numericamente mais expressivas em relação à situação anterior. A FIGURA 6 demonstra uma cena iniciada pelo plano conjunto de câmera em que o conteúdo abordado é o futebol, inclusive esta modalidade foi a única requisitada nas demais situaçóes de aula. No transcorrer da cena, Agenor realiza a arbitragem do jogo seguindo as regras oficiais. Mesmo em se tratando de modalidades diferentes, $\mathrm{o}$ enredo é constituído por jogadas mais habilidosas ao compararmos com o jogo realizado pelas meninas.

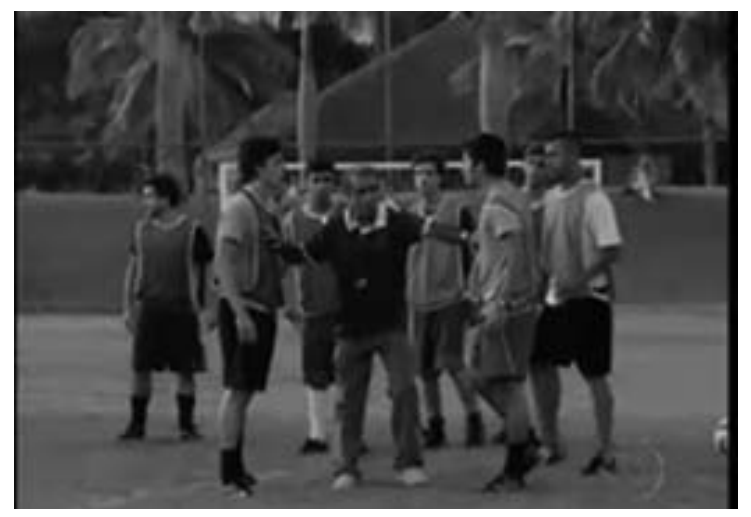

FIGURA 6 - Cena extraída do capítulo exibido no dia 21/04/ 2011.
SOARES ${ }^{31}$ menciona fatos históricos sobre as aulas de educação física sexista e revela a existência de seu caráter discriminatório desde a implantação da disciplina no âmbito escolar. $\mathrm{Na}$ ocasião a caracterização do comportamento feminino e masculino pautava- se exclusivamente em teorias anatômicas e fisiológicas. Segundo a autora eram estabelecidos padróes de comportamento adequados para ambos os sexos, o que explica a separaçáo dos espaços de aula, bem como a diferenciaçáo de conteúdos em futebol para os meninos e voleibol para meninas.

Sobre a naturalização dos significados atribuídos culturalmente ao gênero masculino e feminino, Bourdieu $^{32}$ explica que:

O mundo social constrói o corpo como realidade sexuada e como depositário de princípios de visão e de divisão sexualizantes. Esse programa social de percepção incorporada aplica-se a todas as coisas do mundo, e antes de tudo ao próprio corpo [...] (p.18).

Entretanto, no cotidiano escolar atual é possível constatar esforços significativos rumo à superação da questão. Louro et al..$^{33}$, por exemplo, trabalham no campo teórico desnaturalizando as diferenças atribuídas culturalmente a ambos os sexos. Enquanto isso, embasados em tais argumentaçóes, diversos profissionais optam por outras formas de organização das turmas conforme apontam JEsus et al. ${ }^{34}$, que também constataram a partir de outros estudos, que o posicionamento favorável às aulas mistas é majoritário, ao passo que as aulas separadas por sexo são amplamente contestadas.

No que se refere à dinâmica de aula, ficou explícito que as tomadas de decisão foram concentradas na figura do professor, pois, os alunos não eram convidados a opinar sobre o conteúdo a ser trabalhado, nem mesmo sobre elaboração de regras. Sendo assim, o que transpareceu na relação de Agenor com seus alunos foi o discurso autoritário. Segundo ORLANDI $^{8}$, neste tipo de discurso o locutor, na ocasião o professor, ocupa um lugar que supostamente lhe é de direito ao passo que o ouvinte, na situação os alunos, são colocados onde lhes é de direito e de dever. Darido e Rangel ${ }^{35}$ afirma que este tipo de relação interpessoal é comum no paradigma esportivista das aulas, pois, nelas "os procedimentos empregados são extremamente diretivos, o papel do professor é bastante centralizador e a prática, uma repetição dos movimentos esportivos" (p.4).

Levando em consideração as constataçôes feitas até o momento, retomamos a afirmativa de OrLANDi ${ }^{10}$ sobre a redução do saber discursivo a uma equivalência 
ideológica nas produções midiáticas, e constatamos que de fato isto ocorreu na construção do enredo relativo à educação física presente na $18^{\mathrm{a}}$ temporada de $\mathrm{Ma}$ lhação. Até agora a representação abordada se pauta exclusivamente na técnica e competição.

Outro aspecto a ser considerado diz respeito a uma situação de aula ilustrada na FIGURA 7. Com a utilização do plano conjunto de câmera é possível ver o momento em que Agenor se depara com a problemática ligada ao contágio pelo vírus da AIDS. Isto porque, no treino de futebol dois alunos se chocaram durante uma disputa de bola caindo bruscamente. Um deles, cuja mãe é portadora do vírus HIV, sofre um ferimento. Ninguém o ajuda levantar, diferente do que ocorreu com o companheiro que imediatamente foi amparado.

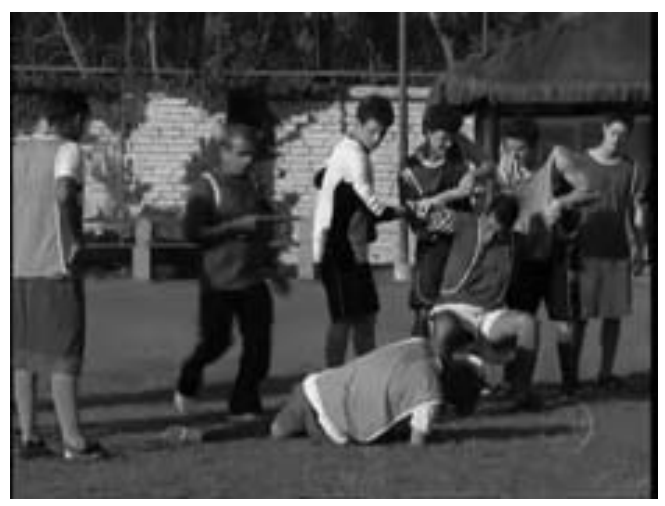

FIGURA 7 - Cena extraída do capítulo exibido no dia 28/04/ 11.

Mesmo afirmando não ser portador do vírus, alguns colegas iniciam uma discussão agressiva pautada em preconceito e medo de sofrer o contágio. Enquanto isso, outros observam sem reação. Logo Agenor interrompe as discussóes, solicita que o aluno ferido saia para cuidar da lesão, em seguida o substitui prosseguindo o treino.

Na cena subsequente, Agenor demonstra perplexidade no gabinete da direção, onde dialoga com Tereza e Vera sobre o acontecido. Alguns trechos de sua fala explanam as dificuldades sentidas:

Agenor: Foi um caos! Um caos!

E o pior que eu sou das antigas, né?

Mas sinceramente eu não sei como... Como me situar numa, numa hora dessas.

Se o garoto realmente tem AIDS, o que eu faço? Tiro do time?

O pior é que a garotada fica assustada, né? Porque num treino como esses todos eles bem água da mesma garrafa! Numa comemoração eles se abraçam suados!
$\mathrm{Na}$ ocasião os esclarecimentos foram prestados pela diretora. Inclusive ela recusou a possibilidade de retirar o aluno do time, justamente porque a escola luta contra a exclusão. Deste modo, observamos que houve preocupação com a produção de sentidos referentes ao preconceito ligado à doença, porém, a estratégia utilizada para lidar com a questão extrapolou o desconhecimento dos alunos. O professor ignorante sobre o assunto e sobre a proposta da escola não soube conduzir a situação.

Os $\mathrm{PCNs}^{23}$ sugerem que a escola trabalhe assuntos ligados a grandes problemáticas sociais, como é o caso da contaminação pelo vírus HIV, indicando se tratar de uma responsabilidade de todas as disciplinas. Este indicativo está presente nos Temas Transversais, especificamente no tópico que abrange questóes ligadas à Orientação Sexual, onde é contemplada a discussão relacionada à AIDS.

Então, considerando que Agenor representa a imagem do professor de educação física, seu aporte de conhecimentos foi colocado em teste, sobressaindo sua perplexidade e desatualização diante dos fatos. Embora náo seja possível controlar os sentidos apropriados pelos telespectadores, Lopes ${ }^{30}$ aponta que existe um "repertório compartilhado" (p.368), ou seja, assuntos com grande probabilidade de serem julgados como importantes pelos grupos que o observam.

Através deste estudo, explicitamos que os sentidos relativos à Educação Física Escolar presentes na $18^{\mathrm{a}}$ temporada de Malhação foram inspirados basicamente na perspectiva técnica e competitiva de ensino. No enredo as situaçóes de aula foram construídas com base em modalidades esportivas diferenciadas para meninos e meninas. Também foi marcante a dificuldade apresentada pelo professor ao lidar com questóes que extrapolavam a dimensão esportiva e técnica, como na situação que demandou do professor a intermediação do conflito gerado pela possibilidade de contágio pelo HIV.

Além disso, na possível tentativa de captar e manter a atenção do público idoso, a telenovela optou pela apresentação de um profissional com quase 70 de idade, fato que se configurou como novidade no contexto do entretenimento. Porém, esta ideia foi abandonada na temporada seguinte. Observamos que a caracterização da professora Paula (personagem da atriz Danielle Winits) foi pautada na beleza e juventude se aproximando dos modelos mais comuns até então.

Assim, concluímos que a abordagem relacionada à educação física presente na $18^{\mathrm{a}}$ temporada de Malhação não apresentou elementos que pudessem 
direcionar a novas significaçóes no que se refere às concepções de ensino. É cabível lembrar que as representações de Educação Física presentes no produto midiático analisado podem ser constatadas nas práticas docentes reais.

Também almejamos que a utilização de conhecimentos específicos da área de comunicação sirva de inspiraçáo para a realizaçáo de outras pesquisas, pois, neste caso foi de grande valia para compreendermos os sentidos explícitos e implícitos presentes no objeto analisado. E por fim, esperamos ter contribuído para que outros pesquisadores atentem para as atuais e futuras abordagens de educação física que certamente se farão presentes nos programas televisivos. A análise e registro de fenômenos deste gênero favorecem o acompanhamento e compreensão dos significados que permeiam as representaçôes ligadas à educação física em cada época.

\title{
Nota
}

a. Informação emitida pela diretora Tereza, personagem interpretada pela atriz Helena Hanaldi, ao longo da entrevista feita com Agenor no capítulo exibido dia 29/12/2010.

\begin{abstract}
The representation of Physical Education in the 18th season of a TV series called "Malhação"

This research focuses on the professional image of physical education on TV series considering the reputation it has acquired over the past few years. The study aims at investigating some meanings given for Physical Education classes in the eighteenth season of "Malhação". The method used was Discourse Analysis. The results showed that the classes were built based on different sports for boys and girls, focusing on technical execution of the movements. Also, the difficulty of the teacher to deal with issues beyond technical approaches was noticed. The casting of an old man to play the role of a physical education teacher could be considered an interesting and original matter; however, it did not remain in the following seasons.
\end{abstract}

KeY Words: Television; Professional image; Old teacher; Technique; Competition.

\section{Referências}

1. Bourdieu P. Sobre a televisão. Rio de Janeiro: Jorge Zahar; 1997.

2. Betti M. Imagem e ação: televisão e a educação física escolar. In: Betti M, organizador. Educação física e mídia: novos olhares, outras práticas. São Paulo: Hucitec; 2003.

3. Pires GL, Lisboa MM, Antunes S, et al. A pesquisa em educação física e mídia: pioneirismo, contribuiçóes e críticas ao "Grupo de Santa Maria”. Movimento. 2008;14:33-52 [citado 15 maio 2011]. Disponível em: http://seer.ufrgs.br/ index.php/Movimento/article/viewArticle/2543.

4. CONFEF. Conselho Federal de Educação Física. Pé na jaca: academia reconhece erro. Rev Educ Fís. 2007:23 [citado 15 maio 2011]. Disponível em: http://www.confef.org.br/extra/revistaef/arquivos/2007/N23_MARÇO/16_PANORAM.PDF.

5. Organizaçôes Globo. Projeto Memória das Organizaçôes Globo. Dicionário da TV Globo: programas de dramaturgia \& entretenimento. Rio de Janeiro: Jorge Zahar; 2003.

6. Gshow.globo.com [homepage]. No clima de volta às aulas, relembre todas as escolas de Malhação. Rio de Janeiro: Globo Comunicaçóes e Participaçóes; 2000-2014 [citado 20 fev 2012]. Disponível em: http://tvg.globo.com/programas/ video-show/Bau-TV/noticia/2012/08/no-clima-de-volta-aulas-relembre-todas-escolas-de-malhacao.html. 
7. Orlandi EP. Discurso e leitura. São Paulo: Cortez; 1993.

8. Orlandi EP. A linguagem e seu funcionamento: as formas do discurso. Campinas: Pontes; 1996.

9. Orlandi EP. Discurso e texto: formulação e circulação dos sentidos. São Paulo: Pontes; 2005.

10. Orlandi EP. Interpretação: autoria, leitura e efeitos do trabalho simbólico. Campinas: Pontes; 2007.

11. Malhação [homepage]. O site de todas as "malhações" da rede globo. 2011 [citado 7 jul 2011]. Disponível em: http:// malhacaoredeglobo.webnode.com.br/walter-breda-agenor.

12. Rose D. Análise de imagem em movimento. In: Bauer MW, Gaskell G. Pesquisa qualitativa com texto, imagem e som: um manual prático. Petrópolis: Vozes; 2002.

13. Hernandes N. A mídia e seus truques: o que jornal, revista, tv, rádio, e internet fazem para captar e manter a atenção do público. São Paulo: Contexto; 2006.

14. Lüdorf SMA, Ortega FJG. Marcas no corpo, cansaço e experiência: nuances do envelhecer como professor de educação física. Rev Interface. 2013;17:661-75. [citado 24 nov 2013]. Disponível em: http://www.scielo.br/scielo.php?pid=S141432832013000300013\&script=sci_arttext.

15. Silva AC, Lüdorf SMA. Possíveis relaçôes entre corpo, saúde e o envelhecimento do professor de educação física. Movimento. 2012;18:187-204. [citado 24 nov 2013]. Disponível em: http://seer.ufrgs.br/index.php/Movimento/ article/view/18807/19070.

16. Courtine JJ. Os Stakhanovistas o narcisismo: body-building e puritanismo ostentatório na cultura americana. In: Sant'anna DB, organizador. Políticas do corpo. São Paulo: Estação Liberdade; 1995.

17. Chevalier J, Gerbrant A. Dicionário de símbolos: mitos, sonhos, costumes, gestos, formas, figuras, cores, números. Rio de Janeiro: José Olympio; 2002.

18. Dela-Silva SC. O telejornal e a telenovela: o discurso realidade-ficção. Estudos em Jornalismo e Mídia. 2008;5:8798. [citado 8 jun 2011]. Disponível em: https://150.162.1.115/index.php/jornalismo/article/viewFile/19846924.2008v5n1p87/10225.

19. Coutinho LM, Quartiero EM. Uma representação midiática de jovem e escola: a telenovela Malhação e seus modos de endereçamento. Rio de Janeiro: ANPEd; 2009. p.1-15. [citado 8 jun 2011]. Disponível em: http://www.anped. org.br/reunioes/32ra/arquivos/trabalhos/gt16-5827--int.pdf.

20. Notícias da TV brasileira: audiência da TV [Internet]. Audiência e perfil do público de malhação. [citado 4 ago 2012]. Disponível em: http://noticiasdatvbrasil.wordpress.com/2012/08/04/audiencia-e-perfil-do-publico-de-malhacao-pntmaio-2012/.

21. Nascimento PRB, Almeida L. A tematização das lutas na educação física escolar: restriçóes e possibilidades. Movimento. 2007;13:91-110. [citado 24 nov 2013]. Disponível em: http://www.educadores.diaadia.pr.gov.br/arquivos/File/2010/ artigos_teses/EDUCACAO_FISICA/artigos/A-tematizacao-das-lutas-na-Educacao-Fisica-escolar.pdf.

22. So MR, Betti M. Saber ou fazer? O ensino de lutas na educação física escolar. IV Colóquio de Pesquisa Qualitativa em Motricidade Humana: as lutas no contexto da motricidade humana. São Carlos, BR. São Carlos: Sociedade de Pesquisa Qualitativa em Motricidade Humana/UFSCar; 2009. p.540-53. [citado 24 nov 2013]. Disponível em: http://www. ufscar.br/ - defmh/spqmh/pdf/2009/so_betti.pdf.

23. Brasil. Secretaria de Educação Fundamental. Parâmetros Curriculares Nacionais: $5^{\mathrm{a}}$ à $8^{\mathrm{a}}$ série: educação física. Brasília: MEC/SEF; 1998.

24. Ghiraldelli Júnior P. Educação física progressista: a pedagogia crítico-social dos conteúdos e a educação física brasileira. São Paulo: Loyola; 1991.

25. Universidade do Estado da Guanabara. Resolução 425/74. [citado 10 out. 2011]. Disponível em: http://www.boluerj. uerj.br/pdf/re_04251974_10071974.pdf.

26. Frizzo G. Os jogos escolares como mecanismos de manutenção e eliminação: uma crítica à lógica esportiva na escola. Movimento. 2013;19:163-80. [citado 24 nov 2013]. Disponível em: http://www.seer.ufrgs.br/index.php/Movimento/ article/viewFile/38628/27449.

27. Hildebrandt-Stramann R. Textos pedagógicos sobre o ensino da educação física. Ijuí: Unijuí; 2001.

28. Kunz E. Transformação didático-pedagógica do esporte. Ijuí: Unijuí; 2004.

29. Bracht V. Sociologia crítica do esporte: uma introdução. Ijuí: Unijuí; 2005.

30. Lopes MIV, Borelli SHS, Resende VR. Vivendo com a telenovela: mediaçôes, recepção, teleficcionalidade. São Paulo: Summus; 2002.

31. Soares CL. Educação física: raízes européias e Brasil. Campinas: Autores Associados; 1994.

32. Bourdieu P. A dominação masculina. Rio de Janeiro: Bertrand Brasil; 2011. 
Cândido CM, et al.

33. Louro GL, Neckel, JF, Goellner SV. Corpo, gênero e sexualidade: um debate contemporâneo na educação. Petrópolis: Vozes; 2003.

34. Jesus ML, Devide FP, Votre S. Apresentação e análise de trabalhos acerca da distribuição dos alunos por sexo nas aulas de educação física escolar. Movimento. 2008;14:83-98. [citado 24 nov 2013]. Disponível em: http://seer.ufrgs.br/ index.php/Movimento/article/view/5754/3360.

35. Darido SC; Rangel IC. A. Educação física na escola: implicaçôes para a prática pedagógica. Rio de Janeiro: Guanabara Koogan; 2005.

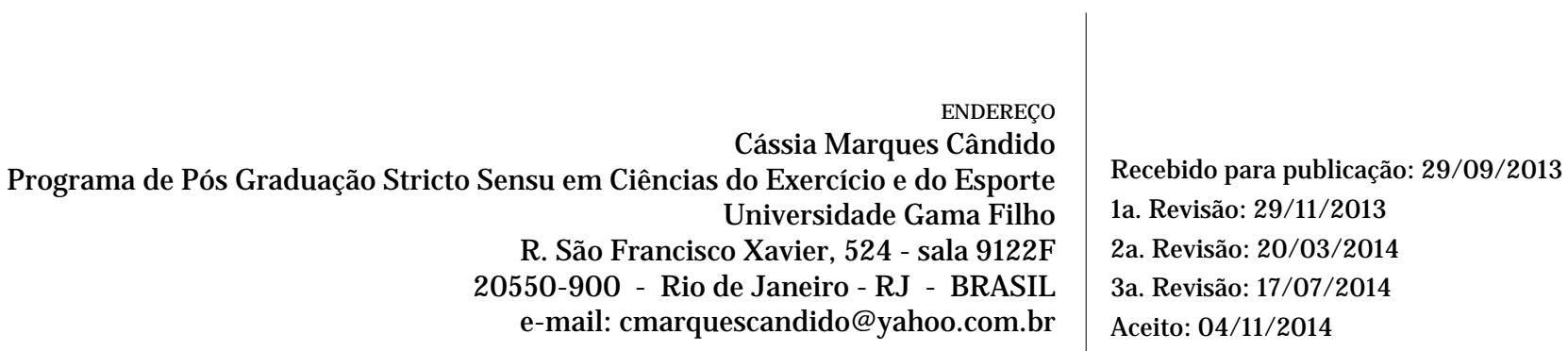

106 • Rev Bras Educ Fís Esporte, (São Paulo) 2015Jan-Mar; 29(1):95-106 